\title{
Fracture Toughness of Vinyl Ester Composites Reinforced with Sawdust and Postcured in Microwaves
}

\author{
H. Ku, ${ }^{1,2}$ M. Prajapati, ${ }^{1}$ and M. Trada ${ }^{1}$ \\ ${ }^{1}$ Faculty of Engineering and Surveying, University of Southern Queensland, Toowoomba, QLD 4350, Australia \\ ${ }^{2}$ Centre of Excellence in Engineered Fibre Composites, University of Southern Queensland Toowoomba, QLD 4350, Australia
}

Correspondence should be addressed to H. Ku, ku@usq.edu.au

Received 22 March 2012; Revised 25 May 2012; Accepted 29 May 2012

Academic Editor: Qing Quan Liang

Copyright (C $2012 \mathrm{H}$. Ku et al. This is an open access article distributed under the Creative Commons Attribution License, which permits unrestricted use, distribution, and reproduction in any medium, provided the original work is properly cited.

\begin{abstract}
A commercial vinyl ester resin supplied by Hetron Chemical Pty. was reinforced with varying percentages by weight of sawdust. The sawdust particles were sieved into 3 different sizes, which were $<300 \mu \mathrm{m}, 300-425 \mu \mathrm{m}$, and $425-1180 \mu \mathrm{m}$, respectively, with a view to increase its fracture toughness for civil and structural applications. The sawdust used varied from $0 \% \mathrm{w} / \mathrm{t}$ to $15 \% \mathrm{w} / \mathrm{t}$ in step of $5 \% \mathrm{w} / \mathrm{t}$. For higher w/t $\%$ of sawdust, the mixture would be too sticky to be mixed and cast. The cast composites were cured in ambient conditions and then postcured in microwave irradiation. They were then tested for fracture toughness using short bar tests. The values of fracture toughness of the composites increased with increasing particulate size, and this is due to the size distribution of the filler. It was found that the optimum amount of sawdust $(425-1180 \mu \mathrm{m}) \mathrm{was} 15 \% \mathrm{w} / \mathrm{t}$, with which the increase in fracture toughness was $126 \%$ as compared to neat resin and the reduction in cost was $15 \%$. Furthermore, the optimum amount of sawdust $(300-425 \mu \mathrm{m})$ was also $15 \% \mathrm{w} / \mathrm{t}$, with which the increase in fracture toughness was $28.3 \%$ as compared to neat resin and the reduction in cost was again $15 \%$.
\end{abstract}

\section{Introduction}

The most commonly used thermosets as composite matrices are unsaturated polyesters, epoxies, and vinyl esters. Unsaturated polyesters dominate the market, whereas epoxies are preferred in high-performance applications. Unsaturated polyesters offer an attractive combination of low price, reasonably good properties, and simple processing. However, basic unsaturated polyester formulations have drawbacks in terms of poor temperature and ultraviolet tolerance. Additives may significantly reduce these disadvantages to suit most applications. Where mechanical properties and temperature tolerance of unsaturated polyesters no longer suffice, the epoxy is often used due to their significant superiority in these respects. These improved properties come at a higher price, and epoxies are most commonly used in areas where cost tolerance is the highest [1]. Epoxy vinyl ester range of resins (vinyl ester resins) was developed in the 1960s [2]. Vinyl esters (VE), as they are usually called, are closely chemically related to both unsaturated polyesters and epoxies and in most respects represent a compromise between the two. They were developed in an attempt to combine the fast and simple crosslinking of unsaturated polyesters with the mechanical and thermal properties of epoxies [1]. The pure vinyl ester resin is brittle and one approach to increase the performance and minimize the cost of the resin is to reinforce it with fillers. As the structural products are cast to shape, the best option to reinforce the vinyl ester resin is to mix it with particulate fillers.

A research centre in the University of Southern Queensland (USQ) manufactures a lot of composite structures for civil engineering applications for local governments and industries at a very competitive cost. A lot of researches have been done in the centre in finding out the most suitable combination of resin and reinforcer; up to date, the reinforcers used include cenospheres (ceramic hollow spheres or SLG), glass powder, calcium carbonate powder, and aluminium powder. This research project is aimed at, investigating the fracture toughness of a commercial resole vinyl ester resin reinforced with sawdust with a view to its 
applications in civil and structural engineering. The sample is simply made by casting the mixture of the resin, initiator, and the sawdust into the moulds.

\section{Materials}

The vinyl ester resin used is Hetron 922 PAS in summer and Hetron 922 PAW in winter. The vinyl ester is dissolved in 50\% by weight of styrene. In this study, Hetron 922 PAW was used. The resin hardener (methyl ethyl ketone peroxide, MEKP) ratio used in this study was $98 \%$ resin by volume and $2 \%$ hardener by volume [3].

The sawdust used was pine waste from sawmills. It has a variety of practical uses, including fuel and manufacturing of the particle board. Until the advent of refrigeration, it was often used in icehouses to keep ice frozen during summer. In terms of hazards, it is flammable when in contact with fire [4]. It was sieved with three different sizes: $<300 \mu \mathrm{m}, 300$ $425 \mu \mathrm{m}$, and $425-1180 \mu \mathrm{m}$. The sawdust particles reduce the weight of the composites, lowering its cost and improving its performance.

The sawdust content in the resin was varied from $5 \% \mathrm{w} / \mathrm{t}$ to $15 \% \mathrm{w} / \mathrm{t}$. Above this percentage, it became very difficult to mix. The sawdust was mixed with the resin without any treatment. MEKP (methyl ethyl ketone peroxide) was the hardener used for curing. Before subjecting the samples for short bar tests, they were cured under ambient conditions for 24 hours and then postcured in microwaves. The MTS 810 universal tensile testing machine was used for the testing.

\section{Fracture Toughness}

Fracture toughness is the maximum stress that a material can withstand if it contains flaws of a certain size and geometry; in other words, it measures the ability of a material containing a flaw to withstand an applied load. A typical fracture toughness test may be performed by applying a tensile stress to a specimen prepared with a flaw of known geometry and size as depicted in Figure 1. The stress applied to the material is intensified at the flaw [5]. The stress intensity factor is

$$
K=f \sigma \sqrt{\pi a},
$$

where $f$ is a geometry factor for the specimen and flaw $\sigma$ is the applied stress, and $a$ is the flaw size.

If the specimen is assumed to have an "infinite" width then $f \cong 1.0$; for "semi-infinite" width, $f \cong 1.1[6,7]$.

The critical stress intensity factor is defined as fracture toughness, $K_{c}$ which is the $K$ required for a crack to propagate and

$$
K_{c}=f \sigma c \sqrt{\pi a} .
$$

$K_{c}$ is a property that measures a material's resistance to brittle fracture when a crack is present and its unit is $\mathrm{MPa} \sqrt{m}$. The value $K_{c}$ for this thick-specimen situation is known as the plane strain fracture toughness $K_{\text {Ic }}$; furthermore, it is also defined by Munz [8]:

$$
K_{\mathrm{Ic}}=f \sigma \sqrt{\pi a}
$$

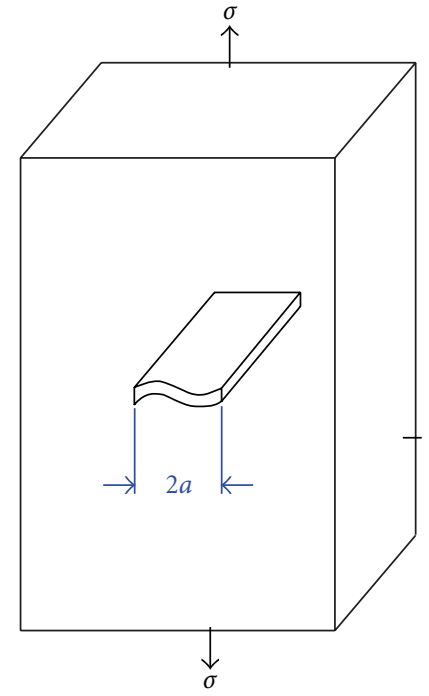

FIGURE 1: Schematic drawing of fracture toughness specimens with edge and internal flaws.

\section{Short Bar Test and the Samples}

Baker described the background, selection criteria, and specimen geometry options for short rod and short bar methods [9]. The background, selection criteria, and specimen geometry options for the samples were clearly explained, which made the manufacture of the samples easier. Figure 2 shows the short rod and short bar specimens with straight chevron slots. The load line is the line along which the opening load is applied in the mouth of the specimen. The specimen parameter, $B$, is the specimen diameter (for short rod) or breath (for short bar). The other parameter, $W$, is the length of the specimen. The relationship between the peak load (to fracture the sample), the breath, and the length of the specimen was given in (4). The equation for fracture toughness in a short bar test can be derived from basic fracture mechanics using the assumptions of linear elastic fracture mechanics (LEFM). The requirements for LEFM were used in this study [9]. The equation for the material plane strain critical stress intensity factor, $K_{\mathrm{ICSR}}[8]$ is

$$
K_{\mathrm{ICSR}}=\frac{\left(F_{\max } Y_{m}^{*}\right)}{B \sqrt{W}},
$$

where $F_{\max }=$ Peak load; $B$ is the breath of the sample; $W$, is the length of the sample; $Y_{m}^{*}$ is the compliance calibration according to ASMT E-399-78 and $Y_{m}=15.7025, \omega=W / H=$ 1.90, $\alpha_{0}=\alpha_{0} / W=0.31, \alpha_{1}=\alpha_{1} / W=0.97$.

All parameters like $a_{0} a_{1}, W$, and $H$ are shown in Figures 2 and 3, respectively. Also, $B=50$ (by design) and $F_{\text {max }}=903 \mathrm{~N}$ (average peak load of six samples of $10 \% \mathrm{w} / \mathrm{t}$ of sawdust (300-425 $\mu \mathrm{m}$ ) reinforced vinyl ester composites). 


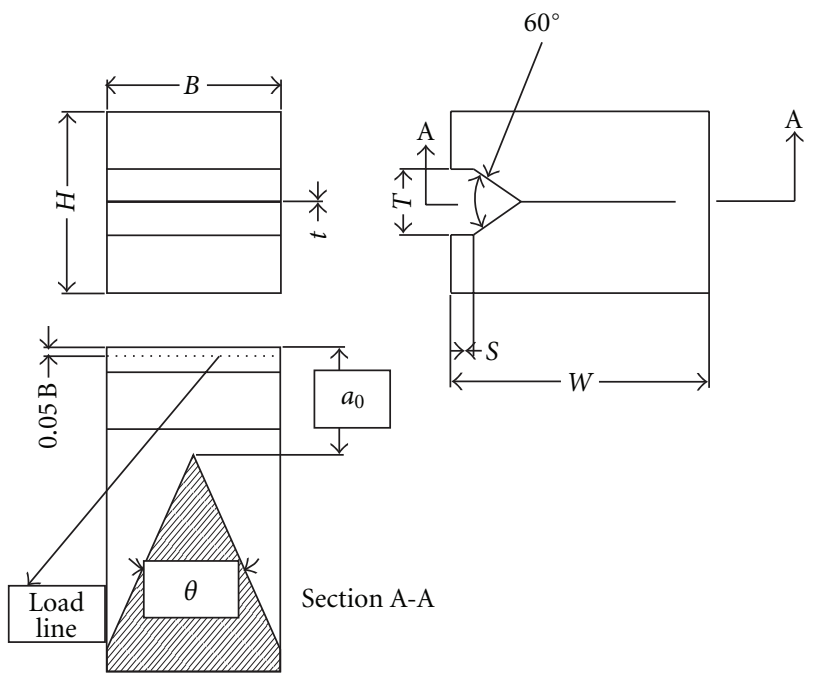

\begin{tabular}{lllc}
\hline Symbol & Definition & Value & Tolerance \\
\hline$B$ & Breadth & $B$ & \\
$W$ & Length & $1.5 B$ & $\pm .010 B$ \\
$H$ & Height & $.870 B$ & $\pm .005 B$ \\
$a_{0}$ & Initial crack length & $.513 B$ & $\pm .005 B$ \\
$\theta$ & Slot angle & 55.2 & $\pm 1 / 2$ \\
$t$ & Slot thickness & See Table 3 & \\
$S$ & Grip groove depth & $.130 B$ & \\
$T$ & Grip groove width & $.313 B$ & $\pm .010 B$ \\
$R$ & Radius of slot cut & See Figure 4 (of & $\pm 2.5 B$ \\
\hline
\end{tabular}

FIGURE 2: Short bar specimen with Straight chevron slots. The load line is the line along which the opening load is applied in the mouth of the specimen.

The fracture toughness for $10 \% \mathrm{w} / \mathrm{t}$ of sawdust $(300$ $425 \mu \mathrm{m})$ was calculated as

$$
\begin{aligned}
K_{\mathrm{ICSR}} & =\frac{\left(F_{\max } Y_{m}{ }^{*}\right)}{B \sqrt{W}} \\
& =\frac{(903 \times 15.7025)}{50 \sqrt{75}}=32.75 \mathrm{MPa} \sqrt{m} .
\end{aligned}
$$

Vinyl ester resin was reinforced with sawdust, and the percentages by weight of sawdust, were varied from $0 \mathrm{wt} \%$ to $15 \mathrm{wt} \%$ in step of $5 \mathrm{wt} \%$ in the cured vinyl ester composite, that is, VE/Sawdust $(\mathrm{X} \%)$, where $\mathrm{X}$ is $\% \mathrm{w} / \mathrm{t}$ of the filler; the $20 \mathrm{wt} \%$ of sawdust was tried but it was too viscous for mixing. The resin was first mixed with the catalyst, after this, the sawdust was added to the mixture, and they were then mixed to give the uncured composite. As the raw materials of the composites were liquid and sawdust particles, the short bar specimens were cast to shape. Table 1 shows the mass in grams of resin, catalyst, and sawdust required, respectively, to make 1000 grams of uncured composite with $15 \mathrm{wt} \%$ of sawdust $(<300 \mu \mathrm{m})$. The mould was made from PVC (polyvinyl chloride) sheets with six pieces of short bar specimens each mould. This is depicted in Figure 4. The slots were made by inserting plastic sheets of suitable thickness. After preliminary curing, the samples were taken out of the mould and postcured in a modified Sanyo microwave oven (Figure 5). The samples were cured at $480 \mathrm{~W}$ for 10 minutes to bring the temperature to $100^{\circ} \mathrm{C}$ and then cooled in the cavity to room temperature. One hundred ${ }^{\circ} \mathrm{C}$ was the highest temperature of heating when the samples were cured conventionally in an electric oven in air [10]. The temperature was measured using an infrared thermometer. These specimens were then subjected to short bar tests. Figure 6 shows one of the VE/Sawdust (X\%) short bar specimens after test.

The number of samples for each percentage by weight of sawdust of particular size range is six. An MTS 810 Material Testing System was used for the test. The rate of extension was $1 \mathrm{~mm}$ per minute. The short bar tests involved an opening load being applied near the mouth of the specimen, causing a crack to initiate at the point of the chevron slot. Ideally, the opening load should be less than the load required to further advance the crack. A continually increasing load must be applied until the crack length reaches 


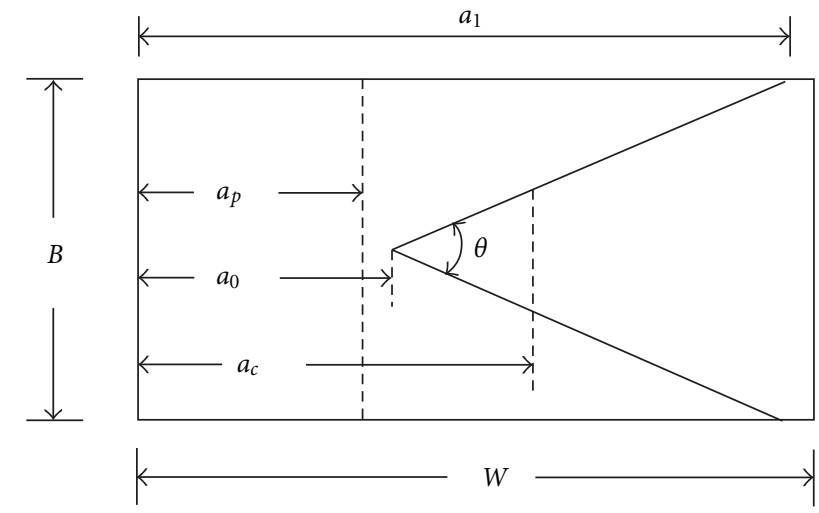

FIGURE 3: Cross-section dimensions of short bar specimen showing $a_{1}$.

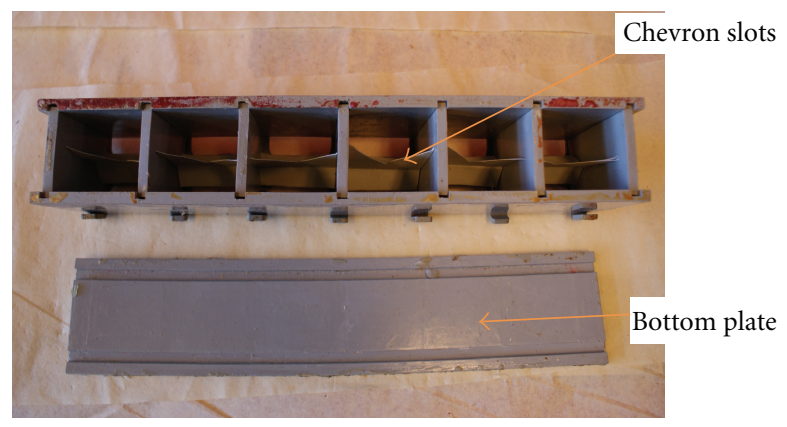

FIgURE 4: The PVC short bar test mould.

the critical crack length, $a_{c}$. Beyond $a_{c}$, the load should decrease, as shown in Figure 7.

\section{Results and Discussion}

Figure 8 shows the fracture toughness of the composite specimens filled with varying percentages by weight of sawdust with diameters of $<300 \mu \mathrm{m}$. It was found that the fracture toughness of neat resin was $27.15 \mathrm{MPa} \sqrt{m}$; the value of fracture toughness increased to $33.31 \mathrm{MPa} \sqrt{m}$ when the sawdust was $5 \% \mathrm{w} / \mathrm{t}$, which was the highest fracture toughness value. The value then decreased again with higher particulate loading. The fracture toughness values for $10 \% \mathrm{w} / \mathrm{t}(26.82 \mathrm{MPa} \sqrt{m})$ and $15 \% \mathrm{w} / \mathrm{t}(27.32 \mathrm{MPa} \sqrt{m})$ of sawdust were more or less the same as that of neat resin $(27.15 \mathrm{MPa} \sqrt{m})$. Table 2 depicts the fracture toughness of $\mathrm{VE} /$ Sawdust $(<300 \mu \mathrm{m})$ with varying percentage by weight of filler with standard deviation in bracket. As the values of the standard deviations were low, it can be argued that the values of fracture toughness were reliable.

The value of fracture toughness of the same filler reinforced phenolic resin (Hexion Cellobond J2027L) was the lowest with the neat resin and was $8.43 \mathrm{MPa} \sqrt{m}$. Its value then increased slowly from $11.39 \mathrm{MPa} \sqrt{m}$ to $11.50 \mathrm{MPa} \sqrt{m}$ as the percentage by weight of sawdust increased from $5 \% \mathrm{w} / \mathrm{t}$ to $10 \% \mathrm{w} / \mathrm{t}$. After this, it increased rapidly to $19.16 \mathrm{MPa} \sqrt{m}$ as

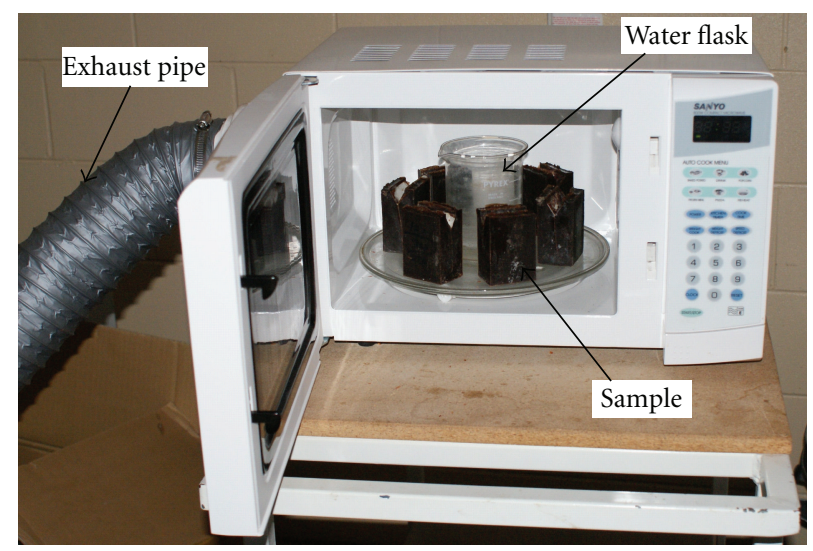

Figure 5: Modified SANYO microwave oven with samples.

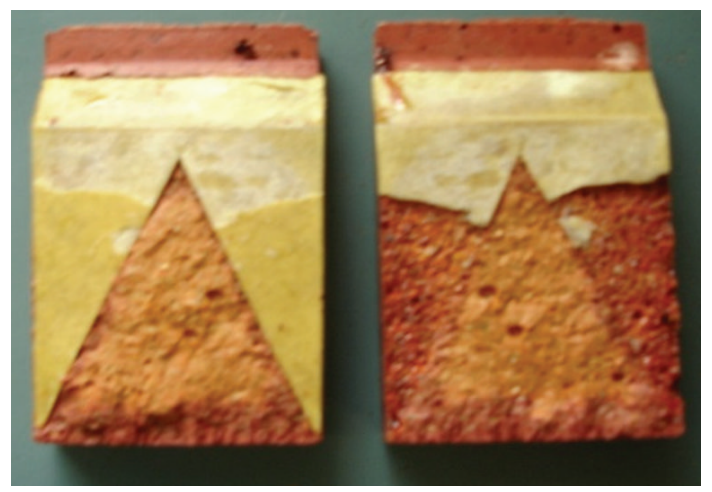

Figure 6: The short bar specimens after testing.

the sawdust increased from $10 \% \mathrm{w} / \mathrm{t}$ to $20 \% \mathrm{w} / \mathrm{t}$, which was $127.3 \%$ higher than that of neat resin [4].

The fracture toughness of neat vinyl ester resin $(27.15 \mathrm{MPa} \sqrt{m})$ is expected to be much higher than its counterpart $(8.43 \mathrm{MPa} \sqrt{m})$ because the former is a higher class resin with higher cost. However, the trends of the curves were not the same; the fracture toughness values of vinyl ester composites peaked at $5 \% \mathrm{w} / \mathrm{t}$ of sawdust and its fracture toughness was $22.7 \%$ higher than that of neat resin (Figure 8). For other percentages by weight of sawdust, the fracture toughness values were within 5 percent markers of that of the neat resin as depicted in Figure 8. On the other hand, the fracture toughness values of sawdust reinforced phenolic composites increased with increasing particulate loading. The fracture toughness of composite with $15 \% \mathrm{w} / \mathrm{t}$ of sawdust $(<300 \mu \mathrm{m})$ was $127 \%$ higher than that of neat (phenolic) resin [4].

Figure 9 illustrates the fracture toughness of the specimens filled with varying percentage by weight of sawdust with diameters of $300-425 \mu \mathrm{m}$. The values and their standard deviations of the fracture toughness were also given in Table 2. As the values of the standard deviations were low, it can be argued that the values of fracture toughness were reliable. It was found that the values of fracture toughness of $5 \% \mathrm{w} / \mathrm{t}$ and $10 \% \mathrm{w} / \mathrm{t}$ by weight of sawdust were $31.14 \mathrm{MPa} \sqrt{m}$ and $32.75 \mathrm{MPa} \sqrt{m}$, respectively; 
TABLE 1: Weight of materials required to make $1000 \mathrm{~g}$ of VE/Sawdust (15\%).

\begin{tabular}{|c|c|c|c|c|c|c|}
\hline Parameters & Materials & $\operatorname{Resin}(\mathrm{R})$ & Hardener $(\mathrm{H})$ & $\mathrm{R}+\mathrm{H}$ & Sawdust & Composite \\
\hline Percentage by weight & & 40 & 1 & - & - & - \\
\hline Percentage by weight & & - & - & 17 & 3 & - \\
\hline Weight of materials in $1000 \mathrm{~g}$ of PF/sawdust (15\%) & & $809.5(\mathrm{~g})$ & $40.5(\mathrm{~g})$ & $850(\mathrm{~g})$ & $150(\mathrm{~g})$ & $1000(\mathrm{~g})$ \\
\hline
\end{tabular}

TABLE 2: Fracture toughness of VE/sawdust with varying particle sizes and percentage by weight.

\begin{tabular}{|c|c|c|c|c|}
\hline & \multicolumn{4}{|c|}{$\mathrm{w} / \mathrm{t} \%$} \\
\hline & $0 \%$ & $5 \%$ & $10 \%$ & $15 \%$ \\
\hline Fracture toughness ( $\mathrm{MPa} \sqrt{m})$, sawdust (<300 microns) & $27.15(1.53)^{\#}$ & $33.31(4.10)$ & $26.82(2.36)$ & $27.32(3.67)$ \\
\hline Fracture toughness ( $\mathrm{MPa} \sqrt{m})$, sawdust (300-425 microns) & $27.15(1.53)$ & $31.14(2.75)$ & $29.86(3.99)$ & $34.83(3.96)$ \\
\hline Fracture toughness (MPa $\sqrt{m})$, sawdust (425-1180 microns) & $27.15(1.53)$ & $38.45(4.12)$ & $50.65(3.30)$ & $61.79(1.90)$ \\
\hline
\end{tabular}

${ }^{\#}$ Standard deviation.

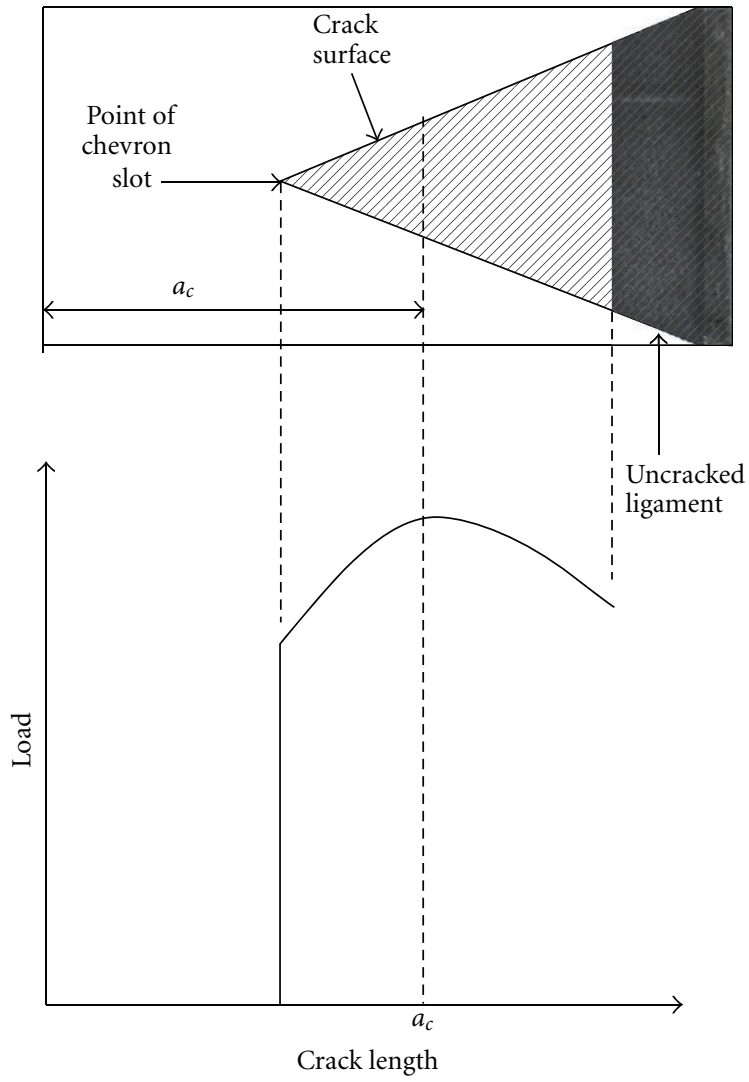

FiguRe 7: Variation of load versus crack length [8].

both, values were within 5 percent markers of that of neat resin $(27.15 \mathrm{MPa} \sqrt{m})$. The fracture toughness of $15 \% \mathrm{w} / \mathrm{t}$ of sawdust was $34.83 \mathrm{MPa} \sqrt{m}$ which was $28.3 \%$ higher than that of neat resin. The fracture toughness of the (300$425 \mu \mathrm{m})$ composites increased with increasing particulate loading.

On the other hand, the values of fracture toughness of the sawdust reinforced phenolic resin increased slowly to $14.46 \mathrm{MPa} \sqrt{m}$ when the sawdust was $10 \% \mathrm{w} / \mathrm{t}$, and to $16.90 \mathrm{MPa} \sqrt{m}$ when the sawdust was $20 \% \mathrm{w} / \mathrm{t}$, which was

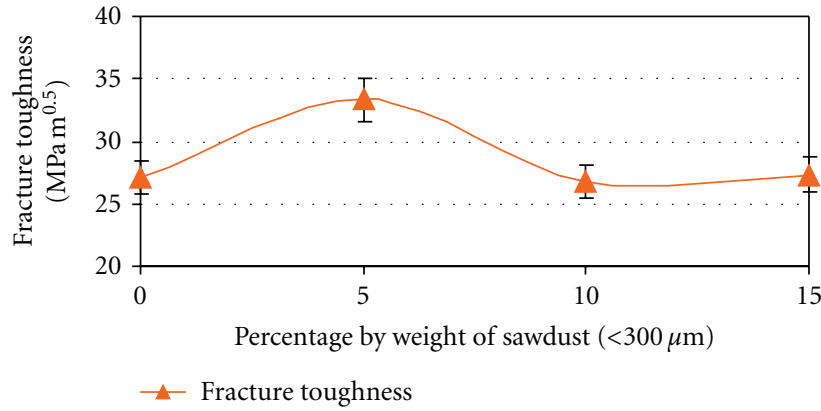

FIGURE 8: Fracture toughness of vinyl ester composites reinforced with sawdust with diameters of $<300 \mu \mathrm{m}$.

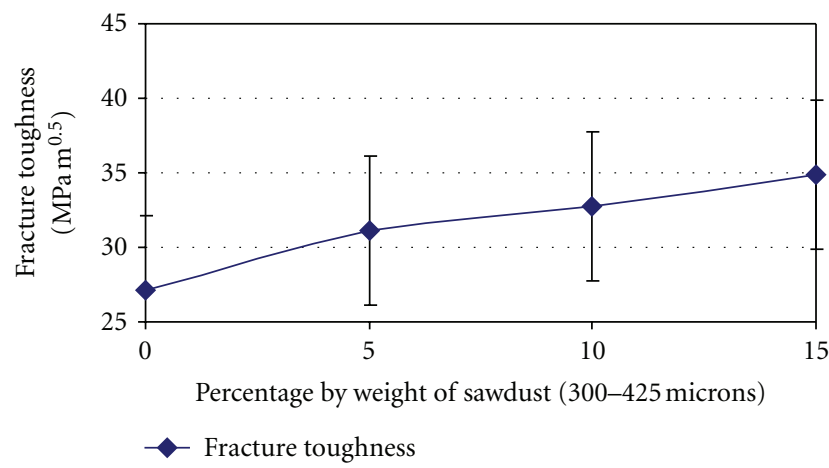

FIGURE 9: Fracture toughness of vinyl ester composites reinforced with sawdust with diameters of 300-425 $\mu \mathrm{m}$.

$100.5 \%$ higher than that of the neat resin. The trend of the curve was increasing with increasing particulate loading as shown in Figure 10. With sawdust particles of 300-425 $\mu \mathrm{m}$ in diameter, the situations were the same as in the case of sawdust with $300 \mu \mathrm{m}$ in diameter; the fracture toughness of phenolic resin increased drastically with increasing reinforcement, while that of vinyl ester resin increased moderately with particulate loading rather than remained stable as in the previous case (Figure 8).

Figure 11 shows the fracture toughness of the specimens reinforced with varying percentage by weight of sawdust of 


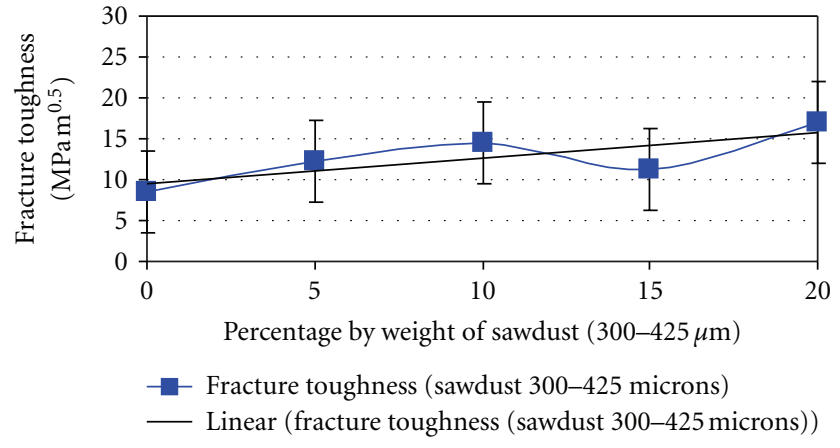

FIGURE 10: Fracture toughness of phenolic composites reinforced with sawdust with diameters of $300-425 \mu \mathrm{m}$.

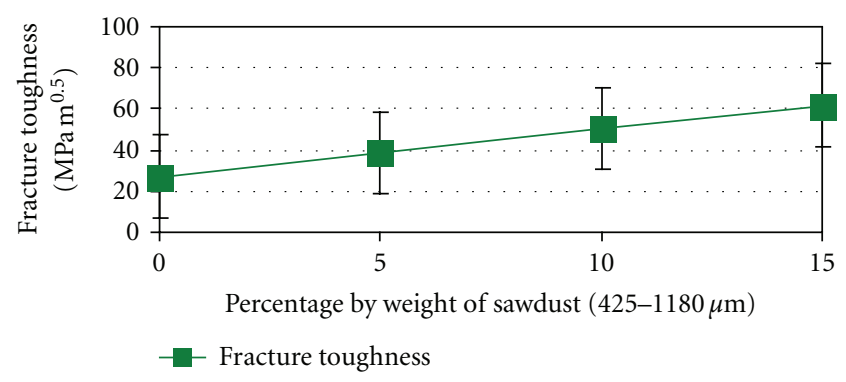

FIGURE 11: Fracture toughness of vinyl ester composites reinforced with sawdust with diameters of $425-1180 \mu \mathrm{m}$.

diameters of $425-1180 \mu \mathrm{m}$. The values and their standard deviations of the fracture toughness were also given in Table 2. As the values of the standard deviations were low, it can be argued that the values of fracture toughness were reliable. The values of fracture toughness increased steadily from $38.45 \mathrm{MPa} \sqrt{m}$ at $5 \% \mathrm{w} / \mathrm{t}$ of reinforcer to $61.79 \mathrm{MPa} \sqrt{m}$ at $15 \% \mathrm{w} / \mathrm{t}$ of filler.

The fracture toughness of phenolic resin reinforced with sawdust of diameters of $425-1180 \mu \mathrm{m}$ was $13.98 \mathrm{MPa} \sqrt{m}$ at $5 \% \mathrm{w} / \mathrm{t}$ of filler; the value then dropped to $11.03 \mathrm{MPa} \sqrt{m}$ at $10 \% \mathrm{w} / \mathrm{t}$ of sawdust loading; it then flattened around this value until the sawdust loading was $20 \% \mathrm{w} / \mathrm{t}$. If trend lines were added, it can be found that the fracture toughness increased slightly with increasing particulate loading.

With reference to Figures 8, 9, and 11, the fracture toughness of the composites increased with increasing diameters of the sawdust; for example, at $15 \% \mathrm{w} / \mathrm{t}$ of sawdust, the values of fracture toughness of the composites increased from $27.32 \mathrm{MPa} \sqrt{m}(<300 \mu \mathrm{m})$ to $34.83 \mathrm{MPa} \sqrt{m}$ $(300-425 \mu \mathrm{m})$ and to $61.79 \mathrm{MPa} \sqrt{m}(425-1180 \mu \mathrm{m})$ with increasing particulate size. From the above discussion, it can be argued that size distribution of the reinforcement plays an important part in increasing the fracture toughness of the composites. In general, the higher the size distribution of the reinforcement, the higher the fracture toughness values. Hameed et al. carried out a study on the effect of size distribution of the fibre on the flexural properties of metallic fibre reinforced concrete (MFRC) and found that the level of improvement in flexural properties of MFRC varied

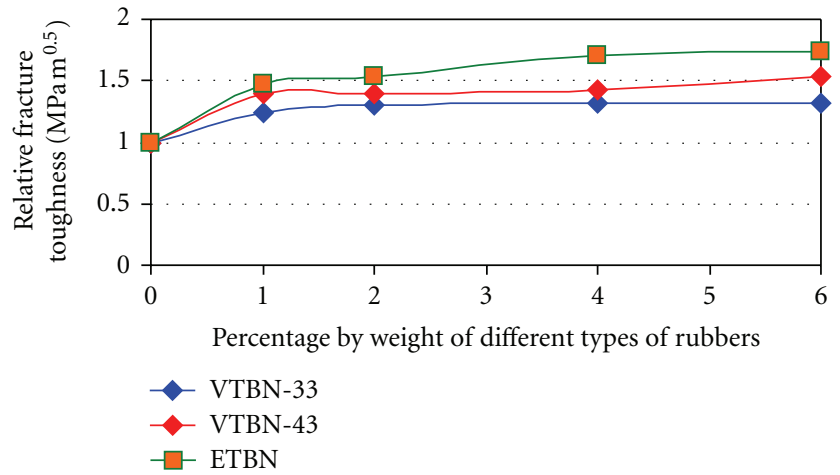

FIGURE 12: The effect of rubber addition on the fracture toughness of vinyl ester specimens, \{adapted from [11]\}.

with the size distribution of the fibres; fibres with larger size distribution showed better efficiency in improving the flexural properties of MFRC [12]. Though the mechanical properties studied in the two cases were different, it can be argued that the higher the size distribution of the reinforcement, the higher the mechanical properties, flexural properties, and fracture toughness.

In another study, a model was developed by Kim to investigate the effects of size distribution of the fibre in short fibre reinforced discontinuous composite materials. The model was based on the theoretical development of conventional shear lag theory developed by Cox. He found that the effect of size distribution of the fibre is significant to composite strengthening through load transfer from the matrix to the fibre and the higher the size distribution of the fibre, the stronger the composites [13].

Dreerman et al. [11] toughened regular vinyl ester and endcapped vinyl ester resins with three types of rubbers: VTBN-33, VTBN-43, and ETBN. VTBN-33 is vinyl terminated rubber with acrylonitrile content of $17 \%$; VTBN43 is vinyl terminated rubber with acrylonitrile content of $16 \%$; ETBN is epoxy terminated rubber, containing $50 \% \mathrm{w} / \mathrm{t}$ styrene. Figure 12 illustrates that the fracture toughness of regular vinyl ester specimens toughened by three types of rubber increased with rubber addition. The ETBN was found as the most effective toughening agent: $5 \% \mathrm{w} / \mathrm{t}$ caused about $70 \%$ increase in fracture toughness, whereas the addition of the same content of VTBN-33 or VTBN-43 resulted in $30 \%$ and $50 \%$ increases, respectively. Most of the fracture toughness improvement was made by the addition of $2 \% \mathrm{w} / \mathrm{t}$ rubber. The general trend of the addition of rubber to the endcapped vinyl ester was the same as the regular vinyl ester: fracture toughness increased with rubber loading; however, gradual increase was found in this case. The ETBN was again the most effective toughening agent, but it was not as effective as in the case of regular vinyl ester: an addition of $10 \% \mathrm{w} / \mathrm{t}$ caused just a $50 \%$ increase in fracture toughness [11]. The general trend of the fracture toughness of this study is the same as that of Dreerman et al.'s study, that is, fracture toughness increases with increasing particulate loading; this is particularly true with sawdust of larger diameters [11]. Salemane et al. [14] discovered that the 


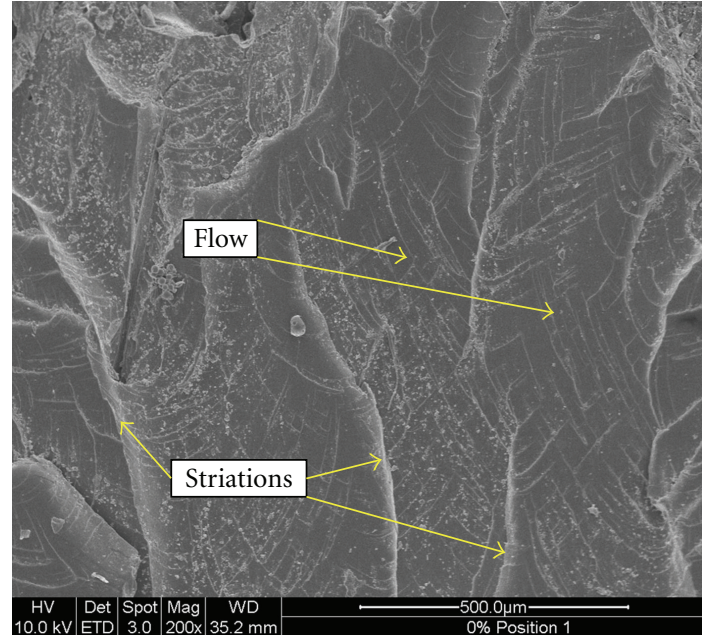

FIGURE 13: Fractured surface of neat vinyl ester resin, 200x.

presence of MAPP (maleic anhydride grafted polypropylene) generally improved the tensile properties of the wood powder reinforced polypropylene composites. Larger wood powder particles gave rise to better tensile properties. This is again true in this study except that fracture toughness replaces tensile properties. However, some other researchers claimed that fine sawdust particles were difficult to disperse, and they agglomerated and behaved as large single particles. Aggregation of particles, especially finer particles, is another factor that can influence the final properties of the composites. Fine or small filler particles were found to improve the mechanical properties, for example, the stiffness of polymer composites more than the large ones. The only drawback to the use of finer particles was their tendency to agglomerate [15-17].

In Dreerman et al.'s study, the values of fracture toughness of neat regular and endcapped vinyl ester resins were $1 \mathrm{MPa} \sqrt{m}$ and $1.55 \mathrm{MPa} \sqrt{m}$, respectively, which were much lower than that $(27.15 \mathrm{MPa} \sqrt{m})$ of the neat vinyl ester used in this study. The vinyl ester neat resin used by Dreerman et al. was Derakane 411-45 based on methacrylated diglycidyl ether of bisphenol A, containing $45 \mathrm{w} / \mathrm{t} \%$ styrene [11]. Dreerman et al.'s work was 10 years ago, and it can be argued that improvement in vinyl ester manufacturing technology has been achieved in that period of time and the fracture toughness of current neat vinyl ester resin would be higher than that used 10 years ago.

5.1. Cost Analysis. The cost of $1 \mathrm{~kg}$ of vinyl ester used was $\$ 10$, and the sawdust was free or nearly free as it is disposed as waste in sawmill. The fracture toughness of the $15 \mathrm{w} / \mathrm{t} \%$ sawdust (300-425 $\mu \mathrm{m})$ reinforced vinyl ester composite was $34.83 \mathrm{MPa} \sqrt{m}$, while that of neat resin was $27.15 \mathrm{MPa} \sqrt{m}$. The increase in fracture toughness was $34.83 \mathrm{MPa} \sqrt{m}-$ $27.15 \mathrm{MPa} \sqrt{m} / 27.15 \mathrm{MPa} \sqrt{m} \times 100 \%=28.3 \%$, and at the same time the reduction in cost was $(1-((0.85 x \$ 10+$ $0.15 x \$ 0) / 1 x \$ 10)) \times 100 \%=15 \%$. The fracture toughness of the $15 \mathrm{w} / \mathrm{t} \%$ sawdust $(425-1180 \mu \mathrm{m})$ reinforced vinyl ester composite was $61.79 \mathrm{MPa} \sqrt{m}$, while that of neat resin

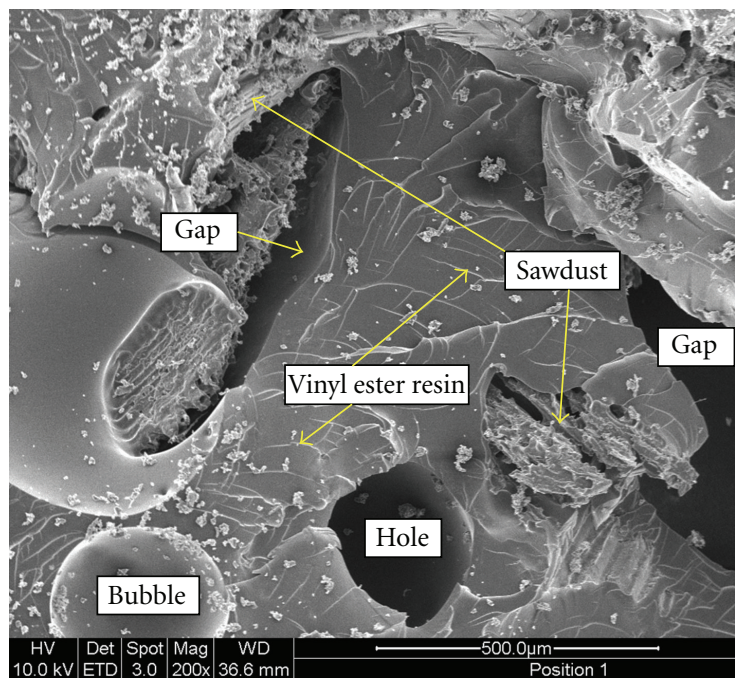

Figure 14: Fractured surface of $5 \mathrm{w} / \mathrm{t} \%$ sawdust $(300-425 \mu \mathrm{m})$ reinforced vinyl ester composite, 200x.

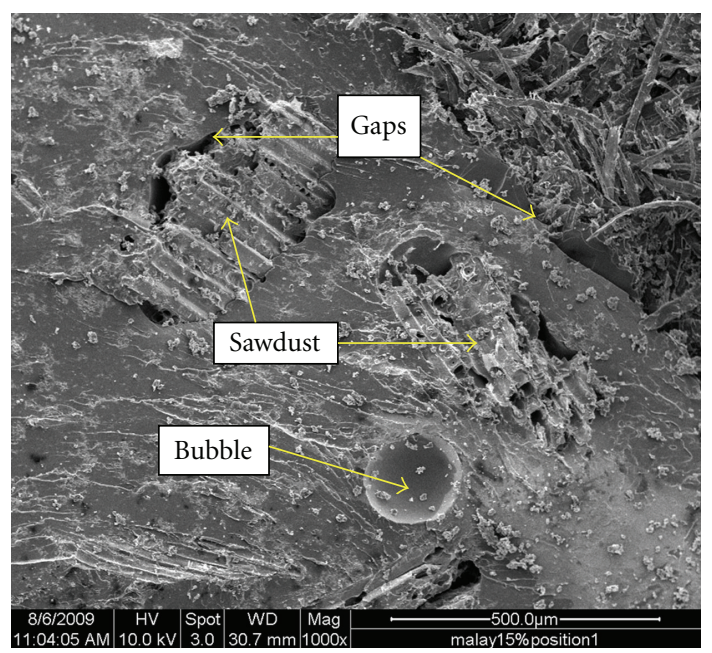

FIGURE 15: Fractured surface of $15 \% \mathrm{w} / \mathrm{t}$ sawdust $(300-425 \mu \mathrm{m})$ reinforced vinyl ester composite, 1000x.

was $27.15 \mathrm{MPa} \sqrt{m}$. The increase in fracture toughness was $(61.79 \mathrm{MPa} \sqrt{m}-27.15 \mathrm{MPa} \sqrt{m}) / 27.15 \mathrm{MPa} \sqrt{m} \times 100 \%=$ $126 \%$, and at the same time the reduction in cost was (1 $((0.85 x \$ 10+0.15 x \$ 0) / 1 x \$ 10)) \times 100 \%=15 \%$.

5.2. Fracture Morphology. Figure 13, magnified at 200 times, illustrates the fractured surface of neat vinyl ester resin, illustrating faint striations followed by a turbulent flow pattern of the fractured zone. The fractured surface is relatively smooth, typical of brittle materials, and it is similar to the fractured surface of neat vinyl ester by other studies $[18,19]$.

Figure 14 shows the fractured surface of $5 \% \mathrm{w} / \mathrm{t}$ sawdust (300-425 $\mu \mathrm{m})$ reinforced vinyl ester composite, 200X. The fracture toughness of this composite was stronger than that of the neat resin because some of the stress was successfully 
transferred to the reinforcer. However, the fracture toughness of this composite was weaker than that of composite with $15 \mathrm{w} / \mathrm{t} \%$ of sawdust (Figure 15) because gaps, bubble, and hole were found. The bubble was due to the evolution of gaseous styrene moieties at the degradation temperature of vinyl ester resin. Bubble and gaps were also found in 15\% w/t of sawdust reinforced vinyl ester composite, but they were smaller as the magnification was $1000 \mathrm{x}$ [20]. With more sawdust and less resin in $15 \% \mathrm{w} / \mathrm{t}$ of sawdust composite, there would be less evolution of gaseous styrene moieties and hence less bubbles. The larger sawdust particles were likely to mingle better with each other and the resin and hence less gaps.

\section{Conclusion}

The values of fracture toughness of the composites increased with increasing particulate size, and this is due to the size distribution of the filler. It was found that the optimum amount of sawdust $(425-1180 \mu \mathrm{m})$ was $15 \% \mathrm{w} / \mathrm{t}$, with which the increase in fracture toughness was $126 \%$ as compared to neat resin and the reduction in cost was 15\%. Furthermore, the optimum amount of sawdust (300-425 $\mu \mathrm{m})$ was also $15 \%$ $\mathrm{w} / \mathrm{t}$, with which the increase in fracture toughness was $28.3 \%$ as compared to neat resin and the reduction in cost was again $15 \%$.

It can be argued that if the composites had not been cured in microwaves but conventionally, the values of the fracture toughness were likely to be lower as in other cases of microwave curing of resins [10, 21]. The fracture toughness of sawdust reinforced vinyl ester resin composites cured in microwaves had been measured and it was found that, in general, the larger the particle size of the reinforcer, and the higher the particulate loadings, the higher the values of fracture toughness. This is due to the fact that sawdust particles with larger size distribution had a better efficiency in improving the fracture toughness of the composites.

\section{References}

[1] L. M. Baker, "Development of the short rod method of fracture toughness measurement," in Proceedings of the Conference on Wear and Fracture Prevention, pp. 163-180, ASM, Metals Park, Ohio, USA, May 1980.

[2] G. Pritchard, Ed., Reinforced Plastics Durability, Woodhead Publishing, UK, 1999.

[3] S. W. Davey, T. Heldt, G. Van Erp, and S. R. Ayers, "Vinylester/ cenosphere composite materials for civil and structural engineering," FRP International, vol. 2, no. 3, pp. 2-5, 2005.

[4] H. Ku, M. Prajapati, and F. Cardona, "Thermal properties of sawdust reinforced vinyl ester composites post-cured in microwaves: a pilot study," Composites Part B, vol. 42, no. 4, pp. 898-906, 2011.

[5] H. S. Ku, S. C. Fok, and E. Siores, "Contrasts on fracture toughness and flexural strength of varying percentages of SLG-reinforced phenolic composites," Journal of Composite Materials, vol. 43, no. 8, pp. 885-895, 2009.

[6] W. D. Callister, Materials Science and Engineering: An Introduction, John Wiley and Sons, New York, NY, USA, 7th edition, 2006.
[7] H. Wang, Engineering Materials—Study Book 1, University of Southern Queensland, 2009.

[8] D. Munz, "Determination of fracture toughness of high strength aluminum alloys with chevron notched short rod and short bar specimens," Engineering Fracture Mechanics, vol. 15, no. 1-2, pp. 231-236, 1981.

[9] L. M. Barker, Mechanics Applied to Brittle Materials, STP 678, ASTM, 1979.

[10] H. Ku, M. Trada, F. Cardona, D. Rogers, and W. Jacobsen, "Tensile tests of phenol formaldehyde SLG reinforced composites post-cured in microwaves: preliminary results," Journal of Composite Materials, vol. 42, no. 26, pp. 2783-2795, 2008.

[11] E. Dreerman, M. Narkis, A. Siegmann, R. Joseph, H. Dodiuk, and A. T. Dibenedetto, "Mechanical behavior and structure of rubber modified vinyl ester resins," Journal of Applied Polymer Science, vol. 72, no. 5, pp. 647-657, 1999.

[12] R. Hameed, A. Turatsinze, F. Duprat, and A. Sellier, "Metallic fiber reinforced concrete: effect of fiber aspect ratio on the flexural properties," Journal of Engineering and Applied Sciences, vol. 4, no. 5, pp. 67-72, 2009.

[13] H. G. Kim, "Effects of fiber aspect ratio evaluated by elastic analysis in discontinuous composites," Journal of Mechanical Science and Technology, vol. 22, no. 3, pp. 411-419, 2008.

[14] M. G. Salemane and A. S. Luyt, "Thermal and mechanical properties of polypropylene-wood powder composites," Journal of Applied Polymer Science, vol. 100, no. 5, pp. 4173-4180, 2006.

[15] B. Tang, "Fibre reinforced polymer composites applications in USA," in Proceedings of the 1st Korea USA Road Workshop, FHWA, January 1997.

[16] K. Oksman and C. Clemons, "Mechanical properties and morphology of impact modified polypropylene-wood flour composites," Journal of Applied Polymer Science, vol. 67, no. 9, pp. 1503-1513, 1998.

[17] K. L. Pickering, A. Abdalla, C. Ji, A. G. McDonald, and R. A. Franich, "The effect of silane coupling agents on radiata pine fibre for use in thermoplastic matrix composites," Composites Part A, vol. 34, no. 10, pp. 915-926, 2003.

[18] D. Ray, D. Bhattacharya, A. K. Mohanty, L. T. Drzal, and M. Mishra, "Static and dynamic mechanical properties of vinylester resin matrix composites filled with fly ash," Macromolecular Materials and Engineering, vol. 291, no. 7, pp. 784792, 2006.

[19] H. Ku, M. Jamal-Eddine, and M. Trada, "Fracture toughness of calcium carbonate powder reinforced vinyl ester composites: pilot study," Journal of Reinforced Plastics and Composites. In press.

[20] F. Cardona, D. Rogers, S. Davey, and G. Van Erp, "Investigation of the effect of styrene content on the ultimate curing of vinylester resins by TGA-FTIR," Journal of Composite Materials, vol. 41, no. 2, pp. 137-152, 2007.

[21] F. Cardona, H. Ku, N. Pattarachaiyakoop, D. Rogers, and M. Trada, "Fracture toughness of phenol formaldehyde composites post-cured in microwaves," Journal of Electromagnetic Waves and Applications, vol. 21, no. 14, pp. 2137-2146, 2007. 

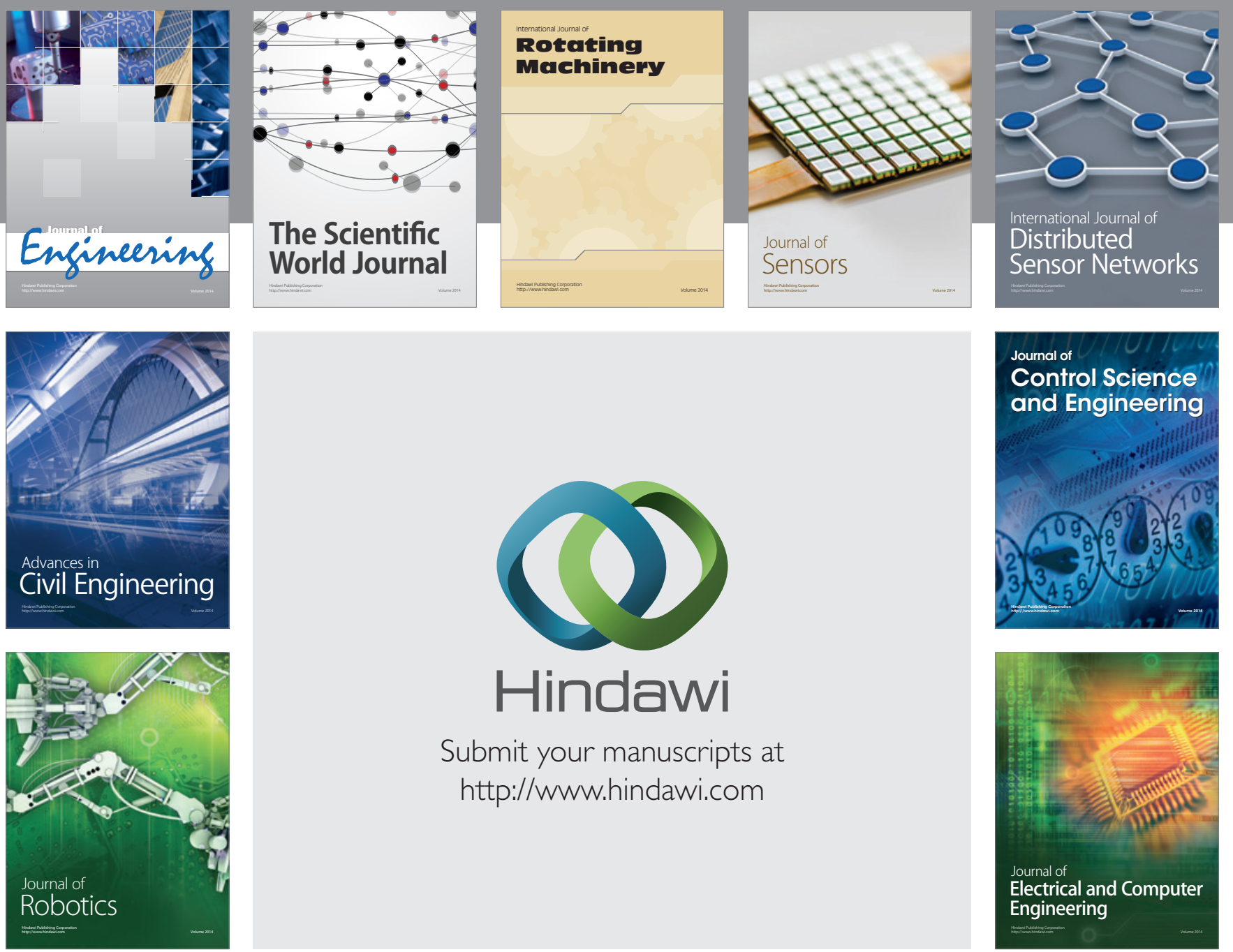

Submit your manuscripts at

http://www.hindawi.com
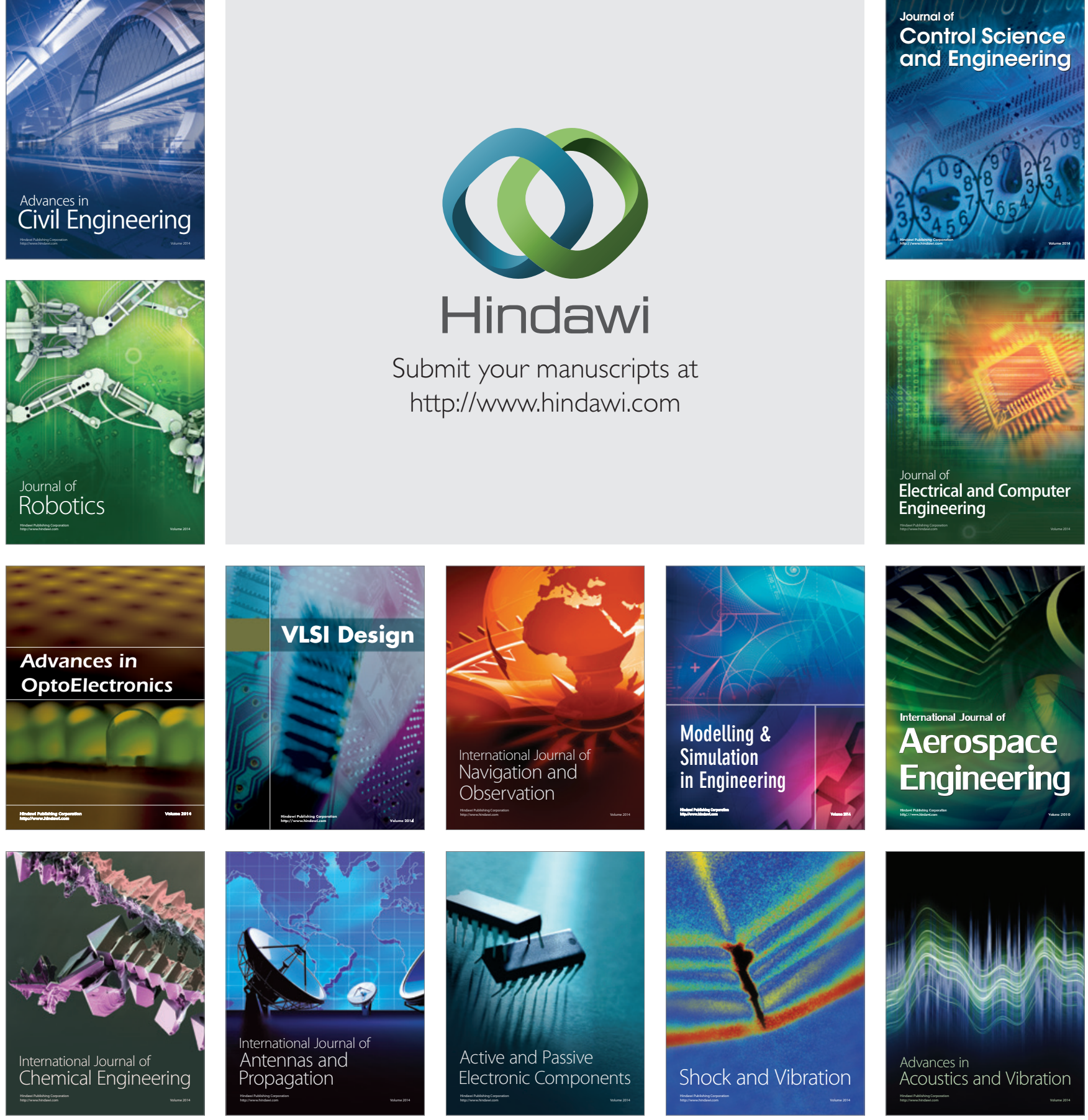